ORIGINAL ARTICLE

\title{
Survival of very preterm infants: Epipage, a population based cohort study
}

\section{B Larroque, G Bréart, M Kaminski, M Dehan, M André, A Burguet, H Grandjean, B Ledésert, C Lévêque, F Maillard, J Matis, J C Rozé, P Truffert on behalf of the Epipage study group}

See end of article for authors' affiliations (n)

Correspondence to: Dr Larroque, INSERM U149, 16 avenue Paul Vaillant Couturier, 94807 Villejuif cedex, France; larroque@vjf.inserm.fr'

Accepted 10 March 2003
Objective: To evaluate the outcome for all infants born before 33 weeks gestation until discharge from hospital.

Design: A prospective observational population based study.

Setting: Nine regions of France in 1997.

Patients: All births or late terminations of pregnancy for fetal or maternal reasons between 22 and 32 weeks gestation.

Main outcome measure: Life status: stillbirth, live birth, death in delivery room, death in intensive care, decision to limit intensive care, survival to discharge.

Results: A total of 722 late terminations, 772 stillbirths, and 2901 live births were recorded. The incidence of very preterm births was 1.3 per 100 live births and stillbirths. The survival rate for births between 22 and 32 weeks was $67 \%$ of all births (including stillbirths), $85 \%$ of live births, and $89 \%$ of infants admitted to neonatal intensive care units. Survival increased with gestational age: $31 \%$ of all infants born alive at 24 weeks survived to discharge, $78 \%$ at 28 weeks, and $97 \%$ at 32 weeks. Survival among live births was lower for small for gestational age infants, multiple births, and boys. Overall, $50 \%$ of deaths after birth followed decisions to withhold or withdraw intensive care: $66 \%$ of deaths in the delivery room, decreasing with increasing gestational age; $44 \%$ of deaths in the neonatal intensive care unit, with little variation with gestational age.

Conclusion: Among very preterm babies, chances of survival varies greatly according to the length of gestation. At all gestational ages, a large proportion of deaths are associated with a decision to limit intensive care.
$\mathrm{C}$ hanges in perinatal management, including increased prenatal referral, prenatal steroid treatment, assisted ventilation at delivery, and surfactant therapy, have been associated with a substantial increase in survival of infants at very low gestational ages. ${ }^{1}$ Immaturity is nonetheless associated with high levels of neonatal morbidity and mortality. Surviving very preterm children appear to have numerous severe disabilities, especially the most immature babies. ${ }^{2}$ Data on survival often come from specialised neonatal units, with a selection bias resulting from different criteria for referral, admission, or treatment. This explains in part the better survival rates, especially for the lowest gestational ages, observed in some single or multiple centre networks than in population based studies. $^{3}$ Evaluation of the effectiveness of perinatal and neonatal care therefore requires studies of geographically defined populations.

Legislation and practice with respect to late terminations of pregnancy for malformation or severe fetal or maternal disease vary according to country. In France there is no age limit for late terminations, and this may affect death and survival rates. ${ }^{4}$

The ethical issues of withholding/withdrawing care for very preterm infants at high risk of death or serious disabilities are also important. A European study of physician practices and attitudes indicates that the vast majority of European neonatologists have been involved in some limitation of intensive care, although the nature of the decision taken varies from one country to another. ${ }^{5}$ Theoretical discussions of the criteria for decision making have been published, and professional guidelines are beginning to appear. In France, a professional group of neonatologists has publish their guidelines, ${ }^{6}$ and the National Consultative Bioethics Committee has published advice (http://www.ccne-ethique.org advice $n 65$ of 9/14/2000). However, there are few studies that report data on actual practices with respect to end of life decisions for babies. ${ }^{5}$ Clinical decisions as well as information to parents need to rely on the most relevant outcome estimates, and no recent population based data were available in France.

We report the conditions at birth and survival of babies born between 22 and 32 weeks in a geographically defined population in France in 1997, stratified by gestational age. The additional role of birth weight, plurality, and sex is also analysed. Finally, deaths associated with limitation of intensive care in the delivery room or the neonatal intensive care unit (NICU) are reported.

\section{PARTICIPANTS AND METHODS}

The study included all births (live births and stillbirths) and late terminations of pregnancy, occurring from 22 to 32 completed weeks gestation, in 1997, to women in the maternity wards of nine French regions, which cover about one third of all births in France. ${ }^{7}$ Information was extracted from obstetric and neonatal records.

Only one private maternity hospital refused to participate. All infants who were transferred to an NICU were included. Data on the vital status of two children of 32 weeks gestation are missing; these two cases are excluded from the tables. Gestational age used in this study is the best obstetric estimate of maturity, reported as the number of weeks of amenorrhoea. 

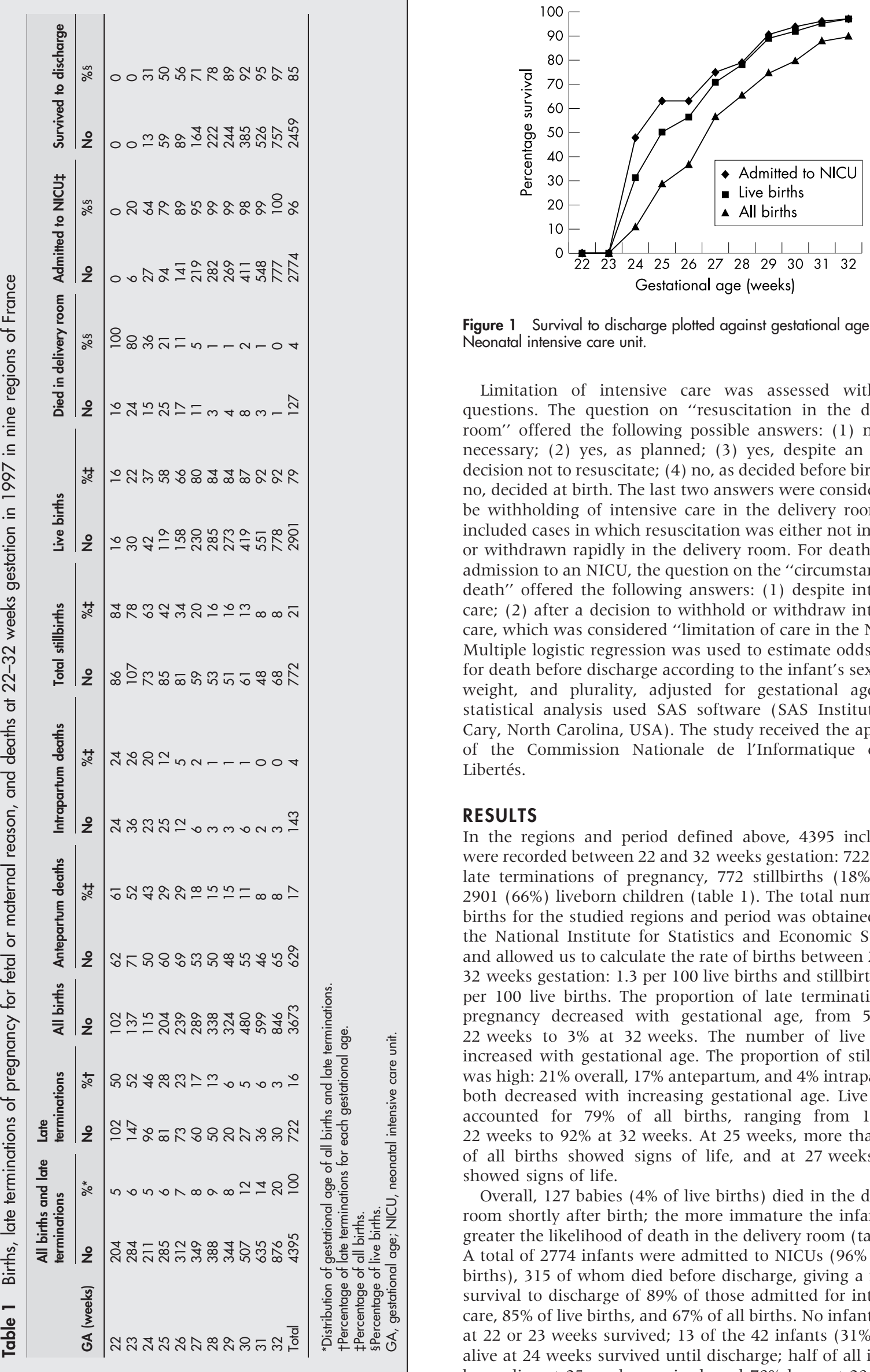

Figure 1 Survival to discharge plotted against gestational age. NICU, Neonatal intensive care unit.

Limitation of intensive care was assessed with two questions. The question on "resuscitation in the delivery room" offered the following possible answers: (1) no, not necessary; (2) yes, as planned; (3) yes, despite an earlier decision not to resuscitate; (4) no, as decided before birth; (5) no, decided at birth. The last two answers were considered to be withholding of intensive care in the delivery room and included cases in which resuscitation was either not initiated or withdrawn rapidly in the delivery room. For deaths after admission to an NICU, the question on the "circumstances of death" offered the following answers: (1) despite intensive care; (2) after a decision to withhold or withdraw intensive care, which was considered "limitation of care in the NICU". Multiple logistic regression was used to estimate odds ratios for death before discharge according to the infant's sex, birth weight, and plurality, adjusted for gestational age. The statistical analysis used SAS software (SAS Institute Inc, Cary, North Carolina, USA). The study received the approval of the Commission Nationale de l'Informatique et des Libertés.

\section{RESULTS}

In the regions and period defined above, 4395 inclusions were recorded between 22 and 32 weeks gestation: 722 (16\%) late terminations of pregnancy, 772 stillbirths (18\%), and 2901 (66\%) liveborn children (table 1). The total number of births for the studied regions and period was obtained from the National Institute for Statistics and Economic Studies, and allowed us to calculate the rate of births between 22 and 32 weeks gestation: 1.3 per 100 live births and stillbirths, 1.1 per 100 live births. The proportion of late terminations of pregnancy decreased with gestational age, from 50\% at 22 weeks to $3 \%$ at 32 weeks. The number of live births increased with gestational age. The proportion of stillbirths was high: $21 \%$ overall, $17 \%$ antepartum, and $4 \%$ intrapartum; both decreased with increasing gestational age. Live births accounted for $79 \%$ of all births, ranging from $16 \%$ at 22 weeks to $92 \%$ at 32 weeks. At 25 weeks, more than half of all births showed signs of life, and at 27 weeks, $80 \%$ showed signs of life.

Overall, 127 babies (4\% of live births) died in the delivery room shortly after birth; the more immature the infant, the greater the likelihood of death in the delivery room (table 1). A total of 2774 infants were admitted to NICUs (96\% of live births), 315 of whom died before discharge, giving a rate of survival to discharge of $89 \%$ of those admitted for intensive care, $85 \%$ of live births, and $67 \%$ of all births. No infants born at 22 or 23 weeks survived; 13 of the 42 infants $(31 \%)$ born alive at 24 weeks survived until discharge; half of all infants born alive at 25 weeks survived, and $78 \%$ born at 28 weeks 
Table 2 Death before discharge of liveborn children by gestational age and birth weight

\begin{tabular}{|c|c|c|c|c|}
\hline \multirow[b]{2}{*}{$\begin{array}{l}\text { Gestational age } \\
\text { (weeks)* }\end{array}$} & \multirow[b]{2}{*}{ Not } & \multicolumn{3}{|l|}{ Birth weight } \\
\hline & & $\begin{array}{l}\text { 10th centile } \\
\text { (g) } \neq\end{array}$ & $\begin{array}{l}<10 \text { th centile } \\
\text { (\% deaths) }\end{array}$ & $\begin{array}{l}\geqslant 10 \text { th centile } \\
\text { (\% deaths) }\end{array}$ \\
\hline 24 & 42 & 550 & 100 & 67 \\
\hline 25 & 117 & 600 & 100 & 45 \\
\hline 26 & 157 & 650 & 67 & 41 \\
\hline 27 & 227 & 660 & 52 & 26 \\
\hline 28 & 282 & 740 & 50 & 19 \\
\hline 29 & 272 & 890 & 23 & 9 \\
\hline 30 & 416 & 980 & 15 & 7 \\
\hline 31 & 546 & 1120 & 12 & 4 \\
\hline 32 & 777 & 1200 & 3 & 3 \\
\hline Total & 2882 & & 27 & 14 \\
\hline
\end{tabular}

*No survivors at 22-23 weeks.

†Number of liveborn infants (19 infants with missing data for birth weight are excluded).

$\$ 10$ th centile of birthweight distribution by week of gestation for liveborn infants of Epipage study.

survived. Figure l shows the survival percentages by gestational age with three different denominators: infants admitted to NICUs, infants born alive, and all births. The difference between survival of all births and live births was about $20 \%$ at $24-26$ weeks, and this decreased to $8 \%$ at $31-$ 32 weeks. The difference between survival of live births and infants transferred to NICU was more than $10 \%$ at 24 25 weeks, and this decreased with gestational age to under $1.5 \%$ at $28-32$ weeks.

Liveborn infants with birth weight less than the 10th centile had a higher death rate than infants with a higher birth weight (table 2). Multiple births accounted for $28 \%$ of all births (table 3 ). At each gestational age, the stillbirth rate was lower and the hospital death rate higher for multiple births than for singletons. In a multivariate model adjusted for gestational age, a birth weight below the 10th centile was significantly associated with an increase in mortality of liveborn infants (odds ratio (OR) $=3.2$ (95\% confidence interval (CI) 2.3 to 4.6$)$ ) for multiple births (OR $=1.3(95 \%$ CI 1.0 to 1.7$)$ ) and for boys ( $\mathrm{OR}=1.3(95 \% \mathrm{CI} 1.0$ to 1.7$)$ ).

Of the 127 deaths in the delivery room, 66\% involved a decision to limit intensive care (table 4 ). This percentage was $89 \%$ for those born at or before 24 weeks and $64 \%$ for infants born at 25-26 weeks. It then decreased at higher gestational ages, except at 31-32 weeks, at which gestational age there were only two deaths of malformed babies. Of the 315 deaths in the NICU, 44\% involved a decision to withhold or withdraw intensive care, with less variation by gestational age. Overall, half the deaths of liveborn infants followed a decision to limit care in either the delivery room or the NICU-from $81 \%$ for those born at 22-24 weeks to about $40 \%$ at $31-32$ weeks.

\section{DISCUSSION}

The strength of this study comes from the population based recruitment of the cohort and the large sample size over a short period, which provides a detailed picture of the birth and survival of infants of 22-32 weeks gestation in the context of current medical practices.

All children admitted to NICUs were included as confirmed from hospital registration. Only one small private maternity hospital refused to participate, where the occasional stillbirth may have occurred. Gestational age was estimated by the obstetric team from all available information (last menstrual period, ultrasound examination, clinical assessments). Ultrasonography during pregnancy is nearly universal in France: the 1998 French national perinatal survey found that $99.8 \%$ of women had at least one ultrasound assessment, and $96.3 \%$ at least three. ${ }^{8}$

Differences in methods (type of study, length of follow up) and actual care (according to time period and country) may account for the wide variations in reported survival rates. ${ }^{3}$ Geographically based population studies that include all births, including stillbirths, produce the most accurate and comparable estimates of gestational age specific mortality. In our study, the overall difference in survival rates according to whether the denominator was all births or live births was $8 \%$ for the whole sample but about $20 \%$ for the lower gestational age groups (fig 1). The accurate identification of an infant as live born in the case of few signs of life also affects both the ratio of stillbirths/live births and neonatal mortality. Calculating survival rates by gestational age based on all births in addition to live births provides interesting information for comparison between studies, but is possible only in geographically based studies that document all deaths before and during delivery. ${ }^{9}{ }^{10}$ Few studies present survival rates including stillbirths. ${ }^{9-11}$ Some include antepartum deaths or differentiate between antepartum and intrapartum deaths, ${ }^{11}$ whereas others include only the latter. ${ }^{9} 1012$

Some studies excluded "lethal congenital malformations", "major malformations", malformations without specifying severity, "antenatally diagnosed malformations", or registered terminations of pregnancy. ${ }^{3}$ We chose to record terminations of pregnancy but to exclude them in the estimation of survival rates. Few data are available to measure the incidence of late terminations, but compared with other European countries, the rate seems to be high in France. ${ }^{4}$

Comparison of the distribution of live births at 2532 weeks in the Paris area in 1985-1986 and in the Epipage

Table 3 Death before discharge by gestational age and plurality

\begin{tabular}{|c|c|c|c|c|c|c|c|c|c|}
\hline \multirow{2}{*}{$\begin{array}{l}\text { Gestational age } \\
\text { (weeks) }\end{array}$} & \multicolumn{4}{|c|}{ All singleton births } & \multicolumn{5}{|c|}{ All multiple births } \\
\hline & No* & Stillbirths (\%)† & Deaths $(\%) \ddagger$ & Deaths (\%)§ & No* & Multiple (\%) | & Stillbirths (\%)† & Deaths $(\%) \ddagger$ & Deaths $(\%) \S$ \\
\hline$\leqslant 24$ & 272 & 77 & 96 & 83 & 82 & 23 & 70 & 98 & 92 \\
\hline $25-26$ & 314 & 43 & 66 & 40 & 129 & 29 & 25 & 69 & 59 \\
\hline $27-28$ & 452 & 22 & 41 & 25 & 171 & 27 & 7 & 32 & 26 \\
\hline $29-30$ & 592 & 16 & 22 & 8 & 212 & 26 & 9 & 20 & 11 \\
\hline $31-32$ & 992 & 10 & 13 & 4 & 449 & 31 & 5 & 7 & 3 \\
\hline Total & 2622 & 24 & 35 & 14 & 1043 & 28 & 14 & 29 & 17 \\
\hline
\end{tabular}

${ }^{*}$ All births (live births and stillbirths).

†Percentage of total births.

fDeaths (stillbirths + deaths in delivery room or neonatal intensive care unit) before discharge as a percentage of all births.

$\S$ Deaths in delivery room or neonatal intensive care unit before discharge as a percentage of liveborn infants.

-Percentage of all births (live births and stillbirths) that were multiple. 
Table 4 Proportions of deaths after a decision to limit (withhold/withdraw) intensive care, by gestational age, among infants born alive

\begin{tabular}{|c|c|c|c|c|c|c|c|c|c|}
\hline \multirow{2}{*}{$\begin{array}{l}\text { Gestational age } \\
\text { (weeks) }\end{array}$} & \multicolumn{3}{|c|}{ Deaths in delivery room } & \multicolumn{3}{|c|}{ Deaths in NICU } & \multicolumn{3}{|c|}{$\begin{array}{l}\text { Deaths in delivery room or } \\
\text { NICU }\end{array}$} \\
\hline & No* & Not & $\% \ddagger$ & No* & Not & $\% \ddagger$ & $\mathrm{No}^{*}$ & Not & $\% \ddagger$ \\
\hline$\leqslant 24$ & 55 & 49 & 89 & 20 & 12 & 60 & 75 & 61 & 81 \\
\hline $25-26$ & 42 & 27 & 64 & 87 & 43 & 49 & 129 & 70 & 54 \\
\hline $27-28$ & 14 & 3 & 21 & 115 & 42 & 37 & 129 & 45 & 35 \\
\hline $29-30$ & 12 & 3 & 25 & 51 & 25 & 49 & 63 & 28 & 44 \\
\hline $31-32$ & 4 & 2 & 50 & 42 & 16 & 38 & 46 & 18 & 39 \\
\hline Total & 127 & 84 & 66 & 315 & 138 & 44 & 442 & 222 & 50 \\
\hline
\end{tabular}

data in $1997^{1314}$ shows that the proportion of births at 2526 weeks has increased from $4 \%$ to $14 \%$, whereas the proportion of births at 30-32 weeks has decreased from $70 \%$ to $60 \%$. Because of the higher proportion of extremely low gestational ages, the global survival rate has increased only slightly, although survival has increased substantially at each gestational age. For comparisons over time and between studies, survival rates by week of gestation are more informative than global mortality.

Infants below the 10th centile of weight for gestational age had a higher risk of mortality. Other studies have reported a similar association. ${ }^{15-19}$ Among liveborn infants, mortality was higher for multiples than singletons. Results of previous studies differ, with some reporting a similar risk excess for multiples, ${ }^{2021}$ no difference, ${ }^{11} 22$ or a lower risk. ${ }^{19}$ These conflicting results could be explained in part by differences in care of multiples between studies: a variable proportion of multiple births may be transferred in utero, with more active care at earlier ages, fewer stillbirths (as we observed), and possibly more postnatal deaths. As in other studies, survival was better for girls than for boys. ${ }^{20-24}$

Differences in perinatal care seriously affect survival rates. Major malformations are the main cause of late termination of pregnancy, and they also contribute substantially to perinatal deaths, the proportion of each varying with national legislation and practices. A higher number of late terminations of pregnancy may reduce the number of fetal and neonatal deaths. In France, late terminations are authorised in case of major malformation or risk to the mother without any limit of gestational age. They represented $16 \%$ of inclusions in the Epipage study, and as much as $50 \%$ at 22 24 weeks. Babies who would have been stillborn with less active obstetric care are alive in the delivery room, and, as they are more frail, they contribute to an increase in neonatal mortality. An active policy of immediate resuscitation reduces the number of early neonatal deaths but may increase both the number of late deaths among these frailer infants and the number of decisions to limit intensive care.

We have attempted to compare gestation specific survival rates of liveborn very preterm infants from geographically based studies in the 1990s (table 5). Some studies report survival to discharge home, ${ }^{11}{ }^{15}{ }^{18}$ and others to one year ${ }^{1025} 26$ and two years of age, ${ }^{27}$ but increasing length of follow up is considered to introduce only limited variations, as most deaths occur before discharge home. The gestation specific survival rates for live births in our study were similar to those in other populations, except for two Australian studies with higher survival rates. ${ }^{15} 27$ Survival rates at 23 weeks range from $0 \%$ to $20 \%$, at 24 weeks from $17 \%$ to $44 \%$, and at 25 weeks from $35 \%$ to $64 \%$; they tended to be more consistent thereafter. These younger gestational ages are also those for which decisions on intensive care are most discussed.

The high incidence of disability among survivors, particularly for the most immature, has prompted much ethical discussion. The interpretation of differences in neonatal mortality statistics is difficult because of the impact of practices of resuscitation at birth and/or limitation of intensive care. Decision making criteria may vary both across and within countries. ${ }^{5}$ These decisions may occur at different

Table 5 Survival rates (\%) of very preterm infants born alive in the 1990s in geographically based studies

\begin{tabular}{|c|c|c|c|c|c|c|c|c|}
\hline & France & Australia & Australia & England & England & Australia & Wales & UK+Ireland \\
\hline Year of birth & 1997 & 1990-1 & $1991-2$ & $1991-3$ & $1991-4$ & $1992-3$ & $1993-4$ & 1995 \\
\hline First author & Epipage & Hagan & VICSG & Bohin & Tin & Sutton & Cartlidge & Costeloe \\
\hline Reference & & 15 & 27 & 11 & 10 & 25 & 26 & 18 \\
\hline No of live births & 2899 & 679 & 401 & 1535 & 560 & 614 & 760 & 1185 \\
\hline Survival & At discharge & At discharge ${ }^{*}$ & At 2 years & At discharge ${ }^{*}$ & At 1 year* & At 1 year & At 1 year & At discharge ${ }^{*}$ \\
\hline \multicolumn{9}{|l|}{$\begin{array}{l}\text { Gestational age } \\
\text { (weeks) }\end{array}$} \\
\hline 22 & 0 & 0 & - & 0 & 0 & 0 & 0 & $1 \dagger$ \\
\hline 23 & 0 & 20 & 10 & 3 & 2 & 2 & 5 & 11 \\
\hline 24 & 31 & 44 & 33 & 28 & 17 & 31 & 19 & 26 \\
\hline 25 & 50 & 64 & 58 & 36 & 35 & 49 & 46 & 44 \\
\hline 26 & 56 & 67 & 72 & 55 & 53 & 66 & 68 & - \\
\hline 27 & 71 & 85 & 77 & 71 & 70 & 79 & 68 & - \\
\hline 28 & 78 & 95 & - & 80 & - & - & 76 & - \\
\hline 29 & 89 & 94 & - & 87 & - & - & 82 & - \\
\hline 30 & 92 & 93 & - & 90 & - & - & 95 & - \\
\hline 31 & 95 & 97 & - & 93 & - & - & 92 & - \\
\hline 32 & 97 & 95 & - & 97 & - & - & - & - \\
\hline
\end{tabular}


stages in time: decisions whether or not to initiate intensive care in the delivery room; various attitudes when the treatment appears futile, or the neurological prognosis too poor. ${ }^{5}$ In the Epipage study, half the deaths in the delivery room or the NICU were reported to have occurred after a decision to limit intensive care. The literature describes only occasionally, and quantifies very rarely, these aspects of perinatal care, the measurement of which is sensitive and difficult. ${ }^{28}$ The EPICure study ${ }^{18}$ reports that, among children under 26 weeks, $55 \%$ of the deaths in the NICU occurred after intensive care was withheld/withdrawn; the corresponding percentage in the Epipage study is very similar: $51 \%$. As expected, in our study, the percentage of deaths after limitation of intensive care was highest for the most immature infants, in both the delivery room and the NICU. In the NICU, however, the percentage of deaths associated with limitation of care remained high at all gestational ages. Whereas only $3 \%$ of those born at 31-32 weeks admitted to the NICU died, $38 \%$ of these deaths followed a decision to withdraw further care. In France, there is some consistency in obstetric and neonatal policies and practices aiming to reduce the risk of survival of extremely handicapped children: in the case of major congenital malformation by termination of pregnancy late in the third trimester, and in the case of poor neurological prognosis in very immature babies by limitation of intensive care.

Currently in France, $1.3 \%$ of babies are born before 33 weeks gestation. The overall survival rate to discharge was $89 \%$ of the infants admitted to intensive care, $85 \%$ of live births, and $67 \%$ of all births. Chances of survival among these babies vary greatly according to the length of gestation. At the lowest gestational ages, a large proportion of deaths follow a decision to limit intensive care for babies with the poorest prognosis. A follow up of this cohort is currently carried out in order to assess the impact of perinatal decisions in care on health and development of very preterm babies.

\section{ACKNOWLEDGEMENTS}

We thank all those who have contributed to the coordination of the study at the national or regional level, all medical doctors and midwifes who took time to fill in the medical questionnaires, and the mothers who agreed to participate in the study.

\section{Authors' affiliations}

B Larroque, G Bréart, M Kaminski, F Maillard, Epidemiological Research Unit on Perinatal and Women's Health, U149 INSERM Villejuif, France

M Dehan, Department of Neonatology, Hôpital Béclère, Clamart, France M André, Maternité Régionale, Nancy, France

A Burguet, Department of Neonatology, Besançon Hospital, Besançon, France

H Grandjean, INSERM U558, Toulouse, France

B Ledésert, Observatoire Régional de la Santé, Montpellier, France C Lévêque, Department of Neonatology, Hôpital Charles Nicolle, Rouen, France

J Matis, Department of Neonatology, Hôpital de Hautepierre,

Strasbourg, France

J C Rozé, Department of Neonatology, Hôpital Mère Enfant, Nantes, France

P Truffert, Department of Neonatology, Hôpital Jeanne de Flandres, Lille, France

Funded by a contract INSERM (National Institute of Health and Medical Research)-Merck-Sharp et Dohme-Chibret, the Fondation de la Recherche Médicale, the Direction Génerale de la Santé of the Ministère des Affaires Sociales.

The Epipage Study Group

INSERM U149: B Larroque (national coordinator), P-Y Ancel, B Blondel, G Bréart, M Dehan, M Garel, M Kaminski, F Maillard, C du Mazaubrun, P Missy, F Sehili, K Supernant

Alsace: M Durand, J Matis, J Messer, A Treisser (Hôpital de Hautepierre, Strasbourg)
Franche-Comté: A Burguet, L Abraham-Lerat, A Menget, P Roth, J-P Schaal, G Thiriez (CHU St Jacques, Besançon)

Haute-Normandie: C Lévêque, S Marret, L Marpeau (Hôpital Charles Nicolle, Roven)

Languedoc-Roussillon: P Boulot, J-C Picaud (Hôpital Arnaud de Villeneuve, Montpellier), A-M Donadio, B Ledésert (ORS Montpellier) Lorraine: $M$ André, J-L Boutroy, J Fresson, P Vert (Maternité Régionale, Nancy)

Midi-Pyrénées: C Arnaud, S Bourdet-Loubère, H Grandjean (INSERM U558, Toulouse), M Rolland (Hôpital des Enfants, Toulouse)

Nord-Pas-de-Calais: C Leignel, P Lequien, V Pierrat, F Puech, D Subtil, P Truffert (Hôpital Jeanne de Flandre, Lille)

Pays-de-Loire: G Boog, V Rouger-Bureau, J-C Rozé (Hôpital MèreEnfant, Nantes)

Paris-Petite-Couronne: P-Y Ancel, G Bréart, M Kaminski, C du Mazaubrun (INSERM U149, Paris), M Dehan, V Zupan (Hôpital Antoine Béclère, Clamart), M Vodovar, $M$ Voyer (Institut de Puériculture, Paris)

\section{REFERENCES}

1 Hack M, Fanaroff AA. Outcomes of children of extremely low birthweight and gestational age in the 1990's. Early Hum Dev 1999;53:193-218.

2 Wood NS, Marlow N, Costeloe K, et al. Neurologic and developmental disability after extremely preterm birth. EPICure Study Group. N Engl J Med 2000;343:378-84

3 Evans DJ, Levene MI. Evidence of selection bias in preterm survival studies: a systematic review. Arch Dis Child Fetal Neonatal Ed, 2001;84, F79-84.

4 Van Der Pal-De Bruin KM, Graafmans W, Biermans MC, et al. The influence of prenatal screening and termination of pregnancy on perinatal mortality rates. Prenat Diagn 2002;22:966-72.

5 Cuttini M, Kaminski M, Garel M, et al. End-of-life decisions in neonatal intensive care. Lancet 2000;356:2190-1.

6 Dehan M, Gold F, Grassin M, et al. Dilemmes éthiques de la période périnatale: recommandations pour les décisions de fin de vie. Arch Pediatr 2001;8:407-19.

7 Larroque B et le groupe Epipage. EPIPAGE: epidemiologic study of very premature infants. Protocol of the survey. [EPIPAGE: étude épidémiologique sur les petits âges gestationnels. Protocole de l'enquête]. Arch Pediatr 2000;7(suppl 2):339-42.

8 Blondel B, Norton J, du Mazaubrun C, et al. Development of the main indicators of perinatal health in metropolitan France between 1995 and 1998. Results of the national perinatal survey. [Evolution des principaux indicateurs de santé périnatale en France métropolitaine entre 1995 et 1998]. J Obstet Gynecol 2001;30:552-64.

9 Lefebvre F, Glorieux J, St-Laurent-Gagnon T. Neonatal survival and disability rate at age 18 months for infants born between 23 and 28 weeks of gestation. Am J Obstet Gynecol 1996;174:833-8.

10 Tin W, Wariyar U, Hey E. Changing prognosis for babies of less than 28 weeks' gestation in the north of England between 1983 and 1994. BMJ 1997:314:107-11.

11 Bohin S, Draper ES, Field DJ. Impact of extremely immature infants on neonatal services. Arch Dis Child Fetal Neonatal Ed 1996;74:F110-13.

12 Allen MC, Donohue PK, Dusman AE. The limit of viability: neonatal outcome of infants born at 22 to 25 weeks' gestation. N Engl J Med 1993:329:1597-601

13 Dehan M, Vodovar M, Goujard J, et al. Future of premature infants of less than 33 weeks gestational age: results of an inquiry undertaken in 1985 in the Paris region. [Devenir des prématurés de moins de 33 semaines d'âge gestationnel: résultats d'une enquête menée en 1985 dans la région parisienne]. J Gynecol Obstet Biol Reprod 1990;19:25-35.

14 Ancel PYA, du Mazaubrun C, Breart G, et al. Multiple pregnancy, place of delivery and mortality in very premature infants: early results from the EPIPAGE cohort in Ile-de-France area. [Résultats de l'enquête Epipage en lle de France]. J Gynecol Obstet Biol Reprod 2001;30(suppl 1):47-54.

15 Hagan R, Benniger H, Chiffings $D$, et al. Very preterm birth: a regional study. Part 2: the very preterm infant. Br J Obstet Gynaecol 1996; 103:239-45.

16 Morley R, Brooke OG, Cole TJ, et al. Birthweight ratio and outcome in preterm infants. Arch Dis Child 1990;65(1 Spec No):30-4.

17 Wilcox AJ, Skjaerven R. Birth weight and perinatal mortality: the effect of gestational age. Am J Public Health 1992;82:378-82.

18 Costeloe K, Hennessy E, Gibson AT, et al. The EPICure study: outcomes to discharge from hospital for infants born at the threshold of viability. Pediatrics 2000;106:659-71

19 Draper ES, Manktelow B, Field DJ, et al. Prediction of survival for preterm births by weight and gestational age: retrospective population based study. BMJ 1999;319:1093-7.

20 Yu VY, Downe L, Astbury J, et al. Perinatal factors and adverse outcome in extremely low birthweight infants. Arch Dis Child 1986;61:554-8.

21 Hoffman EL, Bennett FC. Birth weight less than 800 grams: changing outcomes and influences of gender and gestation number. Pediatrics 1990:86:27-34.

22 Nielsen HC, Harvey-Wilkes K, MacKinnon B, et al. Neonatal outcome of very premature infants from multiple and singleton gestations. Am J Obstet Gynecol 1997; 177:653-9.

23 Synnes AR, Ling EW, Whitfield MF, et al. Perinatal outcomes of a large cohort of extremely low gestational age infants (twenty-three to twenty-eight completed weeks of gestation). J Pediatr 1994;125:952-60. 
24 Jonas HA, Lumley JM. The effect of mode of delivery on neonatal mortality in very low birthweight infants born in Victoria, Australia: Caesarean section is associated with increased survival in breech-presenting, but not vertexpresenting, infants. Paediatr Perinat Epidemiol 1997:11:181-99.

25 Sutton L, Bajuk B. Population-based study of infants born at less than 28 weeks' gestation in New South Wales, Australia, in 1992-3. New South Wales Neonatal Intensive Care Unit Study Group. Paediatr Perinat Epidemiol 1999;13:288-301.
26 Carrlidge PH, Stewart $\mathrm{JH}$. Survival of very low birthweight and very preterm infants in a geographically defined population. Acta Paediatr 1997;86:105-10.

27 The Victorian Infant Collaborative Study Group. Outcome at 2 years of children 23-27 weeks's gestation born in Victoria in 1991-92. J Paediatr Child Health 1997;33:161-5.

28 Kilpatrick SJ, Schlueter MA, Piecuch R, et al. Outcome of infants born at 2426 weeks' gestation. I. Survival and cost. Obstet Gynecol 1997;90:803-8.

\section{This month in the Archives of Disease in Childhood}

The following paper appearing in the March 2004 issue of $A D C$ may be of interest to readers of Fetal and Neonatal.

The neurodevelopmental progress of infants less than 33 weeks into adolescence. F O'Brien, S Roth, A Stewart, L Rifkin, T Rushe, J Wyatt. 